\title{
Digital legitimization of political power
}

\author{
O. A. Ignatieva 1
}

${ }^{1}$ Saint Petersburg State University, 7-9 Universitetskaya Embankment, Saint Petersburg, 199034, Russian Federation

DOI: $10.18255 / 2412-6519-2021-4-358-367$

Research Article

Full text in Russian

The rapid development of information and communication technologies creates new opportunities not only for science, technology and society, but also for political power and governance. Global capitalism is being replaced by platform imperialism. Political power and the state apparatus now have ample opportunities to improve their performance, from the use of algorithmic management based on big data and digital control of the population to increasing trust in the decisions they make by creating the possibility of direct communication between citizens and public authorities through digital platforms. This paper will examine the specifics of legitimizing power through communication platforms, both at the level of a single state and in the international arena. The theoretical framework of this paper is the systematic analysis of D. Easton. Easton. F. Scharpf and W. Schmidt. Also, to understand the peculiarities of platform interaction M. Foucault's concept of governmentality is involved. The work examines not only the peculiarities of the legitimization of power at the national and global level in the era of digitalization, but also analyzes the types of legitimacy of political decisions made through regional and global platforms.

Keywords: digital platform, legitimacy, legitimacy, platform imperialism, transnational corporations, affordances, throughput legitimacy

INFORMATION ABOUT THE AUTHORS

$$
\begin{array}{l|l}
\text { Ignatieva, Olga A. } & \begin{array}{l}
\text { E-mail: o.a.ignatyeva@spbu.ru } \\
\text { Cand. Sc. (Sociology), Associate Professor }
\end{array}
\end{array}
$$

For citation: Ignatieva O. A. Digital legitimization of political power // Social'nye i gumanitarnye znanija. 2021. Vol. 7, No 4. P. 358-367. (in Russ.) 


\title{
Цифровая легитимация политической власти
}

\author{
О. А. Игнатьева ${ }^{1}$
}

${ }^{1}$ Санкт-Петербургский государственный университет, Университетская набережная, 7-9, Санкт-Петербург, 199034, Российская Федерация

DOI: $10.18255 / 2412-6519-2021-4-358-367$

УдК 321.72

Научная статья

Полный текст на русском языке

Бурное развитие информационно-коммуникационных технологий создает новые возможности не только для науки, техники и общества, но и для политической власти и государственного управления. На смену глобальному капитализму приходит платформенный империализм. Политическая власть и государственный аппарат теперь обладают широкими возможностями для повышения эффективности своей работы, начиная от использования алгоритмического управления на основе больших данных и цифрового контроля за населением до повышения доверия к принимаемым ими решениям за счет создания возможности непосредственной коммуникации граждан с органами государственной власти посредством цифровых платформ. В данной статье будут рассмотрены особенности легитимации власти посредством коммуникационных платформ как на уровне отдельно взятого государства, так и на международной арене. Теоретической рамкой данной работы является системный анализ Д. Истона. Ф. Шарпфа и В. Шмидт. Также для понимания особенностей платформенного взаимодействия привлекается концепция управленческой ментальности М. Фуко. В ходе работы не только рассмотрены особенности легитимации власти на национальном и глобальном уровне в эпоху цифровизации, но и проводится анализ типов легитимности политических решений, принимаемых посредством региональных и глобальных платформ.

Ключевые слова: цифровая платформа, легитимность, легитимация, платформенный империализм, транснациональные корпорации, аффордансы, легитимность пропускной способности

ИНФОРМАЦИЯ ОБ АВТОРАХ

\begin{tabular}{l|l} 
Игнатьева, Ольга Анатольевна & $\begin{array}{l}\text { E-mail: o.a.ignatyeva@spbu.ru } \\
\text { Кандидат социологических наук, доцент кафедры } \\
\text { политического управления }\end{array}$
\end{tabular}

Для цитирования: Игнатьева О. А. Цифровая легитимация политической власти // Социальные и гуманитарные знания. 2021. Том 7, № 4. С. 358-367.

\section{Введение}

Первая четверть XXI в. ознаменовалась бурным ростом информационно-коммуникационных технологий, обновление и новации которых ускоряются с каждым годом. Речь идет теперь уже не только о всемирной паутине (Интернет), которая превратила весь мир в глобальную деревню, но и об искусственным интеллекте, алгоритмическом управлении на основе больших данных, участии населения в решении

(C) Игнатьева О. А., 2021

Статья открытого доступа под лицензией СС BY (https://creativecommons.org/licenses/by/4.0/) 
региональных проблем при помощи цифровых платформ, системах цифрового контроля и умных городах. Политическая власть все больше и больше осознает необходимость новых технологий в управлении и использует их как внутри, так и за пределами своих национальных границ.

Интернет создал возможности для распространения нового типа глобальной власти - цифрового империализма, которым овладели страны, являющиеся лидерами в сфере информационно-коммуникационных технологий. Соперничество в цифровой сфере из виртуального стало приобретать реальный характер для национальных властей, которые осознали потенциал бесцензурного Интернета. Использование новых технологий с особой силой поставило на повестку дня вопросы легитимности и легитимации политических решений, принимаемых посредством цифровых платформ. В данной статье будет проведен анализ особенностей легитимации власти посредством коммуникационных платформ как на уровне отдельно взятого государства, так и на международной арене.

\section{Теоретико-методологические основания исследования}

В качестве теоретико-методологической рамки данного исследования выбран системный анализ Д. Истона, Ф. Шарпфа и В. Шмидт. Более подробно использование данного подхода к анализу легитимности платформенных решений будет рассмотрено в следующем разделе. Для понимания сущности платформенного взаимодействия использована концепция управленческой ментальности М. Фуко [1, с. 37]. «Концепция управленческой ментальности демонстрирует рабочую гипотезу Фуко по взаимному конструированию властных техник и форм знания. Семантическая связь управления и способов мышления (ментальности) указывает на то, что невозможно изучать технологии власти без анализа политической рациональности, лежащей в ее основе» [2, p. 191].

Понятие управленческой ментальности можно рассматривать как особый тип рациональности или искусство управления. Наступление цифровой эпохи меняет характер объекта управления. Из рационального субъекта он превращается в движимого импульсами и желаниями. «В то время как либеральная и неолиберальная управленческая ментальность предполагали рационального субъекта, цифровое правительство фокусируется на управлении импульсами и желаниями, создавая, таким образом, цифрового субъекта в противовес либеральному и неолиберальному homo economicus» $[3, \mathrm{p} .1]$.

Целью данной статьи является анализ легитимации власти с использованием цифровых платформ на глобальном и национальном уровнях, что является инновационным подходом в сфере исследований по легитимности и легитимации политической власти. Для достижения данной цели использованы общенаучные методы анализа и синтеза, классификации и систематизации. Работа носит теоретический характер с привлечением отдельных кейсов из сферы платформенного взаимодействия.

\section{Легитимность решений, принимаемых на цифровых платформах}

Прежде чем преступить к анализу легитимации власти посредством цифровых платформ, необходимо разделить понятия «легитимность» и «легитимация». Легитимность относится скорее к восприятию результата политико-управленческого продукта, в то время как легитимация представляет собой процесс обретения доверия политиками, согласия с результатами их деятельности со стороны населения 
национального государства. «Тот факт, что большинство голосов устанавливает легитимность правительства, действительно был общепризнан как процедура, отражающая суть демократии. Такое определение легитимности поначалу казалось естественным, поскольку оно означало окончательный разрыв с прежним порядком вещей, при котором меньшинство диктовало свой закон» [4, p. 1].

В данном разделе статьи будет проанализирована легитимность решений, принимаемых в рамках функционирования глобальных и национальных платформ. В качестве модели для оценки легитимности будет использована таксономия, предложенная американским политологом Вивьен Шмидт [5]. Согласно данной модели, легитимность решений, принимаемых на цифровых платформах, можно разделить на легитимность входа, легитимность пропускной способности и легитимность выхода, что напоминает анализ политического процесса по типу черного ящика [6, p. 38].

Легитимность входа относится к наличию мажоритарного участия в процессе принятия решения, к одобрению со стороны населения принимаемых собственниками платформы решений, отражению интересов пользователей в данных решениях, т. е. на входе ставится вопрос о том, насколько легитимны лица, владеющие платформой, поддержано ли их участие в процессе принятия решения гражданами. Легитимность пропускной способности относится к характеристике процесса принятия решения ответственными лицами, к прозрачности этого процесса, подотчетности собственников платформы и эффективности принимаемых решений. И, наконец, легитимность выхода характеризуется качеством принимаемых решений, отражением в них результатов, ожидаемых населением, которое так или иначе связано с платформой. По мнению В. Шмидт, «Политика выхода и участие на входе могут включать в себя взаимодополняемость и компромиссы, где меньшее качество в одном может быть компенсировано большим качеством в другом» [5, p. 3]. Однако низкая легитимность на входе или выходе не может быть компенсирована высокой легитимностью пропускной способности [7, p. 6].

Если обратиться к легитимности глобальных цифровых платформ на примере Facebook, то можно отметить следующее. В ноябре 2020 г. был создан Наблюдательный совет платформы для контроля за ее контентом. Совет состоит из экспертов разных стран, однако поскольку штаб-квартира находится в США, то он в первую очередь действует в соответствии с их законами и защищает их интересы. У Наблюдательного совета Facebook легитимность входа низкая, поскольку этот орган учрежден частной компанией и осуществляет деятельность без демократического надзора. Легитимность пропускной способности довольно высокая, так как Наблюдательный совет сфокусирован на обеспечении прозрачности, соблюдении законности и подотчётности при модерации контента. Однако данный орган, контролирующий контент Facebook, имеет сомнительную легитимность результатов в основном «из-за его ограниченной сферы деятельности, длительных сроков принятия решений и того факта, что набор ценностей и принципов компании (на основе которых работает Совет) неизбежно вступает в противоречие с ценностями и принципами различных национальных режимов и затрагиваемых групп» [Там же. Р. 8].

В отношении легитимности решений, принимаемых региональными платформами в Российской Федерации, необходимо отметить, что они имеют довольно высокую легитимность входа и выхода. Конечно, решения в ходе платформенного взаимодействия с населением принимаются чиновниками, но представительный орган власти, который оказывает непосредственное влияние на бюрократический аппарат, 
формируется путем всенародного голосования. Представители власти на уровне региона участвуют в принятии решений по вопросам, которые волнуют население, однако проблематика взаимодействия на таких платформах сильно деполитизирована, о чем пойдет речь в соответствующем разделе данной статьи. Процесс принятия решений на цифровых платформах региональных проблем непрозрачен для простого пользователя. Но согласно данным, полученным в ходе исследования по гранту № 20011-31361 РФФИ и АНО ЭИСИ «Аутсорсинг политических суждений: критический анализ информационной парадигмы сетевой публичной коммуникации», алгоритм рассмотрения заявок от населения носит нейтральный характер без применения элементов наджинга и других способов манипулирования поведением пользователей [8, c. 469].

\section{Легитимация власти в контексте платформенного империализма}

Крушение социалистического блока и Советского Союза стало последней возможностью для капиталистических корпораций захватить новые рынки сбыта и резко увеличить свои доходы. Начало нового столетия ознаменовалось не только распространением транснациональных корпораций в глобальном масштабе, но и укреплением новых информационно-коммуникационных технологий в бизнесе, обществе и в государственном управлении. Pantichand Gindin (2004) утверждают, что «как только американское государство двинулось в этом направлении, оно получило новый статус: капитализм эволюционировал в новую форму социального правления, которая обещала и в значительной мере обеспечила (а) возрождение производственной базы американского господства; (б) универсальную модель восстановления условий для получения прибыли в других развитых странах; (в) экономические условия для интеграции глобального капитализма» [9, р. 35-36].

В начале 2000-х гг. транснациональные корпорации в сфере электроники, логистики, нефтедобычи с реальными активами стали уступать свои позиции транснациональным корпорациям, набиравшим влияние в Интернете, - цифровым платформам, таким как Google, Facebook, Amazon, Microsoft.

Власть транснациональных корпораций за счет сверхдоходов начинала соперничать с властью национальных государств, в которых находились либо их штабквартиры, либо представительства. Некоторые исследователи стали полагать, что государство в итоге утрачивает свои позиции как субъект международных отношений. Однако впоследствии это оказалось не так. «Неолиберализм подчеркивает уменьшение роли государства, чтобы гарантировать максимальную прибыль частного сектора. В то время как некоторые страны придерживаются режима малого государственного вмешательства в реализации неолиберальной глобализации, некоторые страны не следуют этой логике. Вместо этого такие страны, как Канада, Китай и Корея, усилили роль государственного регулирования в нескольких областях, особенно в сфере цифровых/социальных технологий в связи со значительной ролью платформ в их странах» [10, p. 94].

Национальные государства не только сделали бизнес транснациональных корпораций статьей доходов, разрешая лоббистскую деятельность данных корпораций для продвижения своих интересов в сфере законодательного регулирования, но и научились использовать бизнес-стратегии этих корпораций для продвижения своего глобального влияния во всем мире. «В 2013 г. Google потратила на лоббирование 14,06 миллионов долларов, что на 14,7 \% меньше, чем в 2012 г., когда компания стала объектом антимонопольного расследования Федеральной торговой комиссии» 
[Там же. Р. 90]. Особенно это касалось движения платформенных корпораций США за свободный, бесцензурный Интернет. «Принцип - жизненно важный для всемирного экспорта американского культурного продукта и американского образа жизни - стал универсальной ценностью как для информационной индустрии, так и для правительства США» [11, p. 440]. Приверженность данному принципу означала распространение не только капиталистического, но и идеологического влияния на другие страны мира, особенно в рамках глобального цифрового разрыва. Так, начал формироваться платформенный империализм, означавший слияние интересов государственной власти США и бизнес-интересов цифровых платформ.

Распространение Интернета и информационно-коммуникационных технологий послужило усилению глобального доминирования Соединенных Штатов в других странах мира. Теперь такая форма цифровизации служила укреплению глобальной власти отдельно взятого национального государства, в котором находилась штаб-квартира соответствующей платформы (платформ). «Согласно платформенному империализму, контроль, владение, известные как глобальное управление, направляемые мощными институтами, отдается промышленно развитым странам со свободным рынком» [10, p. 89].

Цифровые платформы становятся новым типом сосредоточения глобальной власти. На место ТНК с реальными активами приходят цифровые платформы с виртуальными активами. Рейтинг наиболее влиятельных глобальных цифровых платформ можно посмотреть с помощью индекса RDR на сайте https://rankingdigitalrights.org/index2020/ [12]. Первые места рейтинга занимают американские глобальные цифровые платформы: Twitter, Microsoft, Google, Facebook. На восьмом месте рейтинга находятся российские IT-гиганты: Mail.ru, Yandex. Heсмотря на то, что они являются коммерческими структурами, государства, где расположены штаб-квартиры данных компаний, рассматривают их как возможность распространения своего влияния и ценностей на другие страны. Как следствие, они оказывают поддержку на государственном уровне глобальным цифровым платформам с привлечением соответствующих государственных организаций. В качестве примера можно привести конфликт Китая и США по поводу цензуры контента и кибератак со стороны правительства Китая на Google.cn и уход Google из Китая. Защиту интересов Google на государственном уровне США объясняли необходимостью защиты прав и свобод человека, основными носителями и защитниками которых является Америка. К защите интересов платформенной корпорации Google был привлечен государственный департамент и ряд правительственных агентств США. По меткому выражению Hartnett (2011): «Воинствующий гуманизм госсекретаря Клинтон был основан на ряде предположений об американской исключительности: мы являемся моральными лидерами мира, его технологическими и корпоративными хозяевами и единственной нацией, способной и желающей обеспечить верховенство закона» [13, р. 415].

Однако не только государственный департамент США и Конгресс занимаются защитой интересов платформенного бизнеса с целью усиления своего глобального влияния, другие страны, обладающие развитыми цифровыми технологиями, тоже покровительствуют платформенному бизнесу, пытаясь защищать его от влияния американских глобальных платформ. «В разгар конфликта между китайским правительством и Google китайское правительство ограничило обсуждение в Google тем, которые правительство считает неприемлемыми, например, стремление к независимости в регионах Тибет и Синьцзян, а также запрещенное религиозное движение Фа- 
луньгун» [10, p. 84]. Защита информационного пространства КНР при помощи цензуры и государственного регулирования создала возможность для создания собственных глобальных цифровых платформ: Baidu, QQ, Taobao - и распространения культурных ценностей Китая в его зоне влияния.

Чуть позже подобной стратегии стала придерживаться и Российская Федерация, осознав всю опасность для сохранения государственности свободного, бесцен-

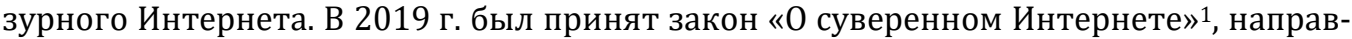
ленный на создание маршрутизации интернет-связи, централизованных инструментов управления, разработку мер безопасности в случае отключения рунета от глобальной Сети. Есть надежда, что реализация данного закона облегчит глобальную конкуренцию нашим лидерам платформенного бизнеса: Yandex, Mail.ru, VKontakte.

Великобритания также решила установить барьеры нерегулируемому потоку информации в Интернете, приняв в апреле 2019 г. Белую книгу - сборник нормативно-правовых актов, направленных на контроль контента в Интернете и своевременное удаление опасных сообщений. Регулирование на основании данного документа будет производить независимый регулирующий орган Великобритании Ofcom. «Ofcom, регулятор связи в Великобритании, будет нести ответственность за устранение «кодексов практики» с подробным описанием того, как компания должна выполнять эту новую обязанность. При этом также ожидается внедрение систем и процессов для повышения безопасности пользователей и их услуг, включая механизмы отчетности и возмещения ущерба» [7, p. 12].

Таким образом, глобальная власть строится на взаимосвязи интересов национальных государств, под юрисдикцией которых находятся штаб-квартиры соответствующих транснациональных корпораций, и самих транснациональных корпораций. Особенно ярко это проявляется при сотрудничестве государства с транснациональными платформенными организациями в феномене, получившем название «платформенный империализм». Возможность глобального идеологического доминирования, легитимируемая распространением ценностей соответствующего национального государства, оказывает влияние на стабильность в обществе и поддержку государственной власти широкими слоями национальной общественности. Государственная власть и платформенная корпорация связаны взаимными интересами: цифровая платформа получает законодательные преференции и поддержку национального государства на международном уровне, в то же время последнее получает постоянный источник дохода и возможность идеологического влияния на другие страны в планетарных масштабах.

\section{Легитимация власти посредством цифровых платформ в Российской Федерации}

Расширение участия населения в вопросах государственного управления посредством создания специализированных цифровых платформ служит важным инструментом легитимации власти. «Официальные цифровые платформы предлагаются субъектами власти с целью вовлечения граждан в управление и оказываются инструментом организации участия. В частности, речь может идти о формировании

\footnotetext{
${ }^{1}$ Федеральный закон от 1 мая 2019 г. № 90-Ф3 «О внесении изменений в Федеральный закон «О связи» и Федеральный закон «Об информации, информационных технологиях и о защите информации» // Российская газета. 07.05.2019. https://rg.ru/2019/05/07/fz90-dok.html (дата обращения: 18.11.2021).
} 
условий активности граждан, принимающих участие в управлении городом с использованием цифровых платформ на примере работы платформы «Активный гражданин»» [14, с. 15].

Государственная власть в России привлекает граждан к обсуждению важных проблем городского (городов федерального значения) и регионального уровня. Возможность обратиться напрямую к чиновнику в режиме онлайн служит важным инструментом для увеличения доверия к региональной власти. Однако обсуждаемые на данных платформах вопросы редко можно назвать остро политическими. В основном они касаются проблем коммунального хозяйства, строительства, дорог, здравоохранения и социальной сферы [15, с. 192-193].

Подобная практика создания цифровых платформ для коммуникации городских властей с населением не нова. В наиболее крупных городах мира тоже существуют городские коммуникационные платформы, позволяющие обсуждать жителям этих городов общие насущные проблемы. Речь идет о таких платформах, как «Talk London» (Лондон, Великобритания, https://www.london.gov.uk/talk-london/); интернет-порталы Барселоны, Испания (https://www.decidim.barcelona/), Рейкъявика, Исландия (https://www.betrireykjavik.is/), реализованных в рамках европейского проекта D-CENT (https://dcentproject.eu/).

B России существует четыре типа цифровых платформ, позволяющих граждан коммуницировать с властью: платформы (разделы сайтов, страницы) обращений граждан, порталы городских (региональных) проблем, порталы оценки инициатив и порталы/платформы общественного участия [16, с. 26-27].

Платформы (часто в виде сайтов или веб-страниц) обращений граждан в органы власти и органы местного самоуправления, созданные в соответствии с Федеральным законом № 59-Ф3, существуют во многих регионах РФ. Обычно они имеют схожую структуру и алгоритм работы по типу «вопрос-ответ», установленные федеральным законодательством. Они являются упрощенным способом цифрового взаимодействия губернатора или главы муниципального образования с проживающим на подведомственной территории населением.

Порталы городских (региональных) проблем также построены по типу «вопрос-ответ» и позволяют гражданам общаться с представителями власти по местным проблемам. Ход рассмотрения запроса можно отслеживать на странице соответствующей платформы. Интернет-порталы городских (региональных) проблем фактически являются развитием цифровых платформ для работы с обращениями граждан. В качестве примера можно назвать цифровую платформу региональных проблем «Наш Санкт-Петербург» (Санкт-Петербург, https://gorod.gov.spb.ru/). Результаты рассмотрения проблемы чиновниками можно оценить там же или отправить вопрос на повторное рассмотрение.

Порталы оценки инициатив являются порталами для оценки и обсуждения инициатив региональных органов власти. Здесь с необходимостью возникает пример платформы «Активный гражданин» (Москва, https://ag.mos.ru/), которая фактически позволяет легитимировать решения Правительства г. Москвы в области нововведений по улучшению функционирования столичной инфраструктуры. Алгоритмы данной платформы содержат элементы геймификации, позволяя проводить голосование граждан, получать статусы и ценные подарки за активное участие в оценке инициатив [17, с. 94].

Порталы/платформы общественного участия не просто являются платформами для обсуждения инициатив региональной администрации, как в случае с порталами оценки инициатив, но и позволяют заинтересованным гражданам предлагать 
свои идеи и проекты по улучшению, например, городской среды. Обычно население, зарегистрированное на платформе, заранее информируют о теме, которая будет обсуждаться в ближайшее время. Когда обсуждение открывается каждый имеет возможность высказать свою идею. Процесс регулируется модератором, который старается «подогреть» дискуссию и облегчить производство идей, задавая наводящие вопросы участникам. Платформы общественного участия пока не получили широкого распространения в России. Одним из немногих примеров является проект «Город идей» (Москва, https://crowd.mos.ru/).

Для активизации участия граждан на всех вышеупомянутых видах платформ (кроме платформы первого типа) создается возможность для выхода в социальные сети, где платформа имеет одноименную группу и позволяет гражданам обсуждать важные региональные проблемы. Это особенно важно в тех случаях, когда аффордансы платформы не предусматривают свободную коммуникацию пользователей [18, с. 159-162]. «Наиболее популярной в регионах России (если исключить порталы обращения граждан по 59-ФЗ) является концепция порталов городских (региональных) проблем. Это хорошо коррелирует с популярной парадигмой сервисного государства, в которой на первый план выдвигается сервисная функция государства» $[16$, c. 27]. Для развития этого подхода в настоящее время Министерством цифрового развития РФ и АНО «Диалог» реализуется проект по внедрению типовой «Платформы обратной связи» в регионах на основе федерального решения «Центр управления регионом».

Таким образом, политическая власть в России на уровне регионов широко использует достижения эпохи цифровизации, создавая соответствующие электронные сферы, которые делают возможным широкое участие населения в решении городских и региональных проблем. Однако тематика обсуждений проблем на данных платформах носит скорее деполитизированный характер.

\section{Заключение}

В эпоху цифровизации политическая власть начинает широко использовать достижения в сфере информационно-коммуникационных технологий. В данной статье мы остановились лишь на одном аспекте применения цифровых технологий властью: использование цифровых платформ глобального и национального уровня. Рассматривая легитимность решений и контента данных платформ, можно утверждать, что платформы регионального уровня коммуникации населения и власти обладают большей легитимностью, чем глобальные платформы, от существования которых выигрывает государственная власть, но собственниками которых являются транснациональные корпорации. Легитимация власти на уровне национального государства достигается за счет привлечения к решению проблем широких слоев населения, однако тематика данных проблем в России носит деполитизированный характер. На глобальном уровне власти национальных государств апеллируют к интересам и ценностям своего населения, продвигая их посредством расширения сферы влияния платформенных корпораций. Данное исследование задает направления анализа цифровой легитимации, которые могут быть углублены заинтересованными исследователями, работающими в данной сфере.

\section{Ссылки / References}

1. Фуко М. Надзирать и наказывать: рождение тюрьмы. M.: Ad Marginem, 1999. 480 с. 
2. Lemke Th. 'The birth of bio-politics': Michel Foucault's lecture at the College de France on neoliberal governmentality // Economy and Society. 2001. Vol. 17. № 2. P. 190-207. http://dx.doi.org/10.1080/03085140120042271

3. Barry L. The rationality of the digital governmentality // Journal for Cultural Research. 2020. № 4. P. 11-16. DOI: 10.1080/14797585.2020.1714878.

4. Rosanvallon P. Democratic legitimacy: Impartiality, Reflexity, Proximity. New Jersy: Princeton University Press, 2011. 227 p.

5. Schmidt V. A. Democracy and legitimacy in the European Union revisited: Input, output and "throughput" // Political Studies. 2013. Vol. 61. № 1. P. 2-22. https://doi.org/ 10.1111/j.14679248.2012.00962.x

6. Easton D. The analysis of Political Structure. New York: Routledge, 1990. 336 p.

7. Haggart B., Keller C. I. Democratic legitimacy in global platform governance // Telecommunication Policy. 2021. Vol. 45. № 6. P. 1-17. https://doi.org/10.1016/j.telpol.2021.102152

8. Игнатьева О. А. Цифровая управленческая ментальность: партисипаторное управление Vs. Биополитика // Политэкс. Политическая экспертиза. 2020. T. 16. № 4. С. 462-473. https://doi.org/10.21638/spbu23.2020.403

9. Pantitch L. and Gindin S. Global Capitalism and American Empire // Social Register. 2004. Vol. 40. № 1. P. 1-38.

10. Jin D. Y. Digital Platforms, Imperialism and Political Culture. New York: Routledge, 2015. 193 p.

11. Schiller N. G. Transnational social fields and imperialism: Bringing a theory of power to Transnational Studies // Anthropological theory. 2005. Vol. 5. Issue 4. P. 439-461.

12. 2020 Ranking Digital Rights Corporate Accountability Index. URL: https://rankingdigitalrights.org/index2020/ (дата обращения: 20.09.2021).

13. Hartnett S. J. Google and the "Twisted Cyber Spy" affair: US-Chinese communication in an age of globalization // Quarterly Journal of Speech. 2004. Vol. 97. № 4. P. 411-434.

14. Шиповалова Л. В. Власть, общество, эксперты - трансформация связей в эпоху цифровых технологий // Государство и граждане в электронной среде. Выпуск 4. Труды XXIII Международной объединенной научной конференции «Интернет и современное общество», IMS-2020, Санкт-Петербург, 17-20 июня 2020 г. Сборник научных статей. СПб: Университет ИТМО, 2020. C. 11-19. DOI: 10.17586/2541-979X-4-11-19.

15. Быков И. А. Деполитизация социально-значимых проблем в цифровых платформах государственного управления // Медиа в современном мире. 60-е Петербургские чтения. Сборник материалов международного научного форума. В 2 т. СПб, 2021. С. 192-193.

16. Городские коммуникационные платформы: критический анализ управленческой технологии / А. Г. Барышкин, И. А. Быков, О. А. Игнатьева, К. С. Кондратенко // Управленческое консультирование. 2021. № 1. С. 20-31.

17. Сморгунов Л. Блокчейн как институт процедурной справедливости // Полис. Политические исследования. 2018. № 5. С. 88-89. DOI: 10.17976/jpps/2018.05.08

18. Сморгунов Л. В., Игнатьева О. А., Быков И. А., Кондратенко К. С., Барышкин А. Г. Публичная коммуникация граждан и органов государственной власти: формирование суждений на цифровых платформах // Вестник Пермского университета. Политология. 2021. T. 15. № 2. С. 156-172. 